\title{
Anemia prevalence \& effect on feto-placental axis with treatment with iron, folic acid \& protein powder
}

\author{
Nagar N. ${ }^{1}$, Mazumdar M. ${ }^{2}$ \\ ${ }^{1}$ Dr. Nidhi Nagar, Assistant Professor, ${ }^{2}$ Dr. Mita Mazumdar, Associate Professor; both authors are affiliated with \\ Department of Obstetrics and Gynaecology, R.K.D.F. Medical College \& Hospital, Bhopal.
}

Corresponding Author: Dr. Mita Mazumdar, Associate Professor, Department of Obstetrics and Gynaecology, R.K.D.F. Medical College \& Hospital, Bhopal, India. E-mail: mita1873@gmail.com

\begin{abstract}
Aim To find out the specific nutritional deficiency in the pregnant anaemic mothers and to see the improvement in birth weight and placental weight with haematinic, folate and antihelminthics. Materials and Methods: Total 111 patients were studied at $24 \pm 4$ weeks of gestation with a view to know etio-pathogenesis of anaemia in pregnancy by serum iron, folate and protein studies. Patients with $\mathrm{Hb}$ less than $8.5 \mathrm{~g} \%$ were given oral haematinics and protein and followed up to the term. Their maternal cord blood and placentae were collected at the time of delivery to see the effect of therapy on foeto-placental axis. Results: Out of 88 anaemic mothers 85 (96.6\%) had either serum iron or folate deficiency or both. $19.3 \%$ patients had pure iron deficiency.Incidence of pure folate deficiency was $37.5 \%$ and $39.8 \%$ combined iron and folate deficiency. Control group with haemoglobin $\geq 11.0 \mathrm{~g} \%$ had significant number of women with folate, iron, or deficiency of both. We have observed significant rise in placental weight \& birth weight of newborn after hematinic \& protein therapy. Conclusion: Serum iron, and folate studies should be done to detect early deficiency ofironand folate as haemoglobin is not a true indicator of early deficiency. Correction of anaemia with haematinics and proteins provides a reasonable good indicators of their deficiency in pregnancy. The severe anaemia was associated with low proteins and albumin indicating that severe anaemia often coexists with hypoproteinamia
\end{abstract}

Keywords: Hypoproteinamia, Folate, Feto-palcentalaxis, Anthelminthic therapy

\section{Introduction}

A recent I.C.M.R. study has shown that more than 50 per cent of women have nutritional anaemia in the later months of pregnancy. For the ultimate control of such wide spread anemia, it is important to isolate the role or each nutrient in its pathogenesis. Fetal programming occurs when the normal pattern of fetal development is disrupted by an abnormal stimulus or 'insult' applied at a critical point in in utero development. Correction of anaemia with haematinics provides adequate proof of a nutritional deficiency in its pathogenesis.

The effects of anemia on the foeto-placental axix have been reported to be placental hypertrophy reduced foetal birth weight, and increased incidence of prematurity and perinatal mortality. Hypoxia, oxidative and nitrative stress all alter placenta development and may be a general underlying mechanism that links altered placental function to fetal programming $[1,2]$.

Manuscript received: $5^{\text {th }}$ February 2019

Reviewed: $15^{\text {th }}$ February 2019

Author Corrected: $20^{\text {th }}$ February 2019

Accepted for Publication: $24^{\text {th }}$ February 2019
Anaemia in pregnancy, defined as a haemoglobin concentration $(\mathrm{Hb})<110 \mathrm{~g} / \mathrm{L}$, affects more than 56 million women globally, two thirds of them being from Asia. Multiple factors lead to anaemia in pregnancy, nutritional iron deficiency anaemia (IDA) being the commonest. Underlying inflammatory conditions, physiological haemodilution and several factors affecting $\mathrm{Hb}$ and iron status in pregnancy lead to difficulties in establishing a definitive diagnosis. IDA is associated with increased maternal and perinatal morbidity and mortality, and long-term adverse effects in the new born[3]

Strategies to prevent anaemia in pregnancy and its adverse effects include treatment of underlying conditions, iron and folate supplementation given weekly for all menstruating women including adolescents and daily for women during pregnancy and the post partum period, and delayed clamping of the umbilical cord at delivery. Oral iron is preferable to intravenous therapy for treatment of IDA. B12 and 


\section{Original Research Article}

folate deficiencies in pregnancy are rare and may be due to inadequate dietary intake with the latter being more common. These vitamins play an important role in embryo genesis and hence any relative deficiencies may result in congenital abnormalities [4,5].

An attempt has been made in this study to find out the specific nutritional deficiency in the pregnant anaemic mothers. It has also been possible to follow a group of mothers by treating their anaemia at 20-28 weeks gestation and to evaluate the results of such therapy of comparing the better foeto-placental reserves of iron and folic acid at term and lesser incidence of prematurity, as against the untreated cases.

\section{Methodology}

Type of Study: Prospective study

Setting: Maternity unit, Department of Obstetrics \& Gynaecology R.K.D.F. Medical College \& Hospital, Bhopal.

Inclusion Criteria: Mothers at $24 \pm 4$ weeks of gestation.

\section{Exclusion Criteria}

a. Subjects with primary cardiac, renal and hepatic disorder.

b. Women with history of pathologic blood loss at any stage during pregnancy

One hundred and eleven mothers at $24 \pm 4$ weeks of gestation were selected from the maternity unit, Department of Obstetrics \& Gynaecology R.K.D.F. Medical College \& Hospital, Bhopal. All the women were subjected to investigation from venous blood as described later. The women selected in these studies were groups as follows:

Supplemental group: [Group I: The women with haemoglobin level $6 \mathrm{~g}$ per cent. Group 2: Hb 6-8.5 $\mathrm{gm} / \mathrm{dl}$. Both group I \& II were given oral haematinics in following composition and protein therapy to see the effect or treatment on Foetoplacetal axis

Test Group: [Group III test]Women between 8.5 to $11 \mathrm{~g} \mathrm{per} / \mathrm{dl}$ were chose for etiopathogenesis of anaemia in pregnancy.

Control Group: [Group IV control] 23 women with hemoglobin $11.0 \mathrm{~g}$ per cent or above served as control. Oral haematinic was given in form of Ferettes tablets with following composition. Ferrous Fumerate B.P., $0.25 \mathrm{~g}$ Folic acid I.P., $3.0 \mathrm{mg}$. Cyanocobalamine I.P. 5 $\mathrm{mg}$. Ascorbic acid I.P.50 mg.

These tablets were given one tablet three times daily after meals. Along with above oral, haematinic tablets, protein about 15-20 g was also supplemented to each of these patients. These patients were regularly followed and delivered in the hospital to collect placenta, cord blood, maternal blood samples. The maternal blood was collected in first stage of labour.

Clinical history of each mother was taken and examination was conducted. Care was taken to exclude systemic disease affecting foetal growth. Stool and urine examinations were also done along with biochemical estimations mentioned later.

The patients with hemoglobin $8.5 \mathrm{~g}$ per cent or less were designated as treated cases and were treated with oral haematinics and proteins as described. After clinical history and examination, maternal blood collected for haemoglobin, haematiocrit, transferrin saturation, serum iron, iron binding capacity, total proteins, albumins and serum folate.

All the patient with hamemoglobin $6.0 \mathrm{~g}$ per cent or less were admitted prior to the treatment. They were given treatment for parasitic infestation if they had, along with oral heamtinics and proteins. Blood transfusion was also given in some of these patients. All these patients were discharged after clinical and haematological improvement. All the patients with haemoglobin $8.5 \mathrm{~g}$ per cent or below were regularly followed in antenatal clinic and were again readmitted at the time of delivery to collect maternal blood, cord blood and placenta.

Immediately after completion of second stage of labour about $10 \mathrm{ml}$. of cord blood was collected without milking the cord in aheparinized vial.

The above-mentioned biochemistry was repeated in cord blood. As soon as the placenta was delivered, cord was cut close to the base and the membranes were trimmed off.

Adherent blood clots were removed from the maternal surface of the placenta and sub-choriontic vessels were emptied off by gentle pressure.

The placenta was blotted several times with filter paper and then it was weighed using the same weighing machine for all the cases. 


\section{Results}

Table-1: Haemoglobin, haematocrit and serum protein levels in different maternal hemoglobin groups.

\begin{tabular}{|c|c|c|c|c|c|}
\hline Group & $\begin{array}{c}\text { Range of } \\
\text { haemoglobin } \\
(\mathrm{g} \%)\end{array}$ & $\begin{array}{c}\text { Haemoglobin } \\
(\mathrm{g} \%)\end{array}$ & $\begin{array}{c}\text { Haemotocrit } \\
(\%)\end{array}$ & $\begin{array}{c}\text { Total serum } \\
\text { proteins }(\mathrm{g} \%)\end{array}$ & $\begin{array}{c}\text { Serum } \\
\text { albumin }(\mathrm{g} \%)\end{array}$ \\
\hline $\begin{array}{c}\text { I [supplemental } \\
\text { group] }\end{array}$ & $\begin{array}{l}\leq 6.0 \\
(25)\end{array}$ & $\begin{array}{c}4.6 \\
\pm 0.97\end{array}$ & $\begin{array}{c}13.5 \\
\pm 2.84\end{array}$ & $\begin{array}{c}4.8 \\
\pm 0.75\end{array}$ & $\begin{array}{c}2.4 \\
\pm 0.49\end{array}$ \\
\hline $\begin{array}{c}\text { II [supplemental } \\
\text { group] }\end{array}$ & $\begin{array}{c}6.1-8.5 \\
(21)\end{array}$ & $\begin{array}{c}7.1 \\
\pm 0.64\end{array}$ & $\begin{array}{c}22.3 \\
\pm 2.30\end{array}$ & $\begin{array}{c}5.5 \\
\pm 1.10\end{array}$ & $\begin{array}{c}3.0 \\
\pm 1.02\end{array}$ \\
\hline III [test] & $\begin{array}{c}8.6-10.9 \\
(42)\end{array}$ & $\begin{array}{c}9.7 \\
\pm 0.69\end{array}$ & $\begin{array}{c}29.4 \\
\pm 2.60\end{array}$ & $\begin{array}{c}5.6 \\
\pm 1.05\end{array}$ & $\begin{array}{c}3.0 \\
\pm 1.02\end{array}$ \\
\hline IV [control] & $\begin{array}{l}\geq 11.0 \\
(23)\end{array}$ & $\begin{array}{c}12.6 \\
\pm 0.67\end{array}$ & $\begin{array}{c}36.4 \\
\pm 2.42\end{array}$ & $\begin{array}{c}5.5 \\
\pm 0.69\end{array}$ & $\begin{array}{c}2.9 \\
\pm 0.46\end{array}$ \\
\hline \multicolumn{2}{|c|}{ Total Observation } & 8.7 & 25.9 & 5.4 & 2.9 \\
\hline \multicolumn{2}{|c|}{111} & \pm 2.89 & \pm 8.44 & \pm 0.97 & \pm 0.85 \\
\hline \multicolumn{6}{|c|}{$P$ value } \\
\hline I/IV & & $<0.001$ & $<0.001$ & $<0.005$ & $<0.001$ \\
\hline II/IV & & $<0.001$ & $<0.001$ & n.s. & n.s. \\
\hline III/IV & & $<0.001$ & $<0.001$ & n.s. & n.s. \\
\hline $\begin{array}{l}\text { Correlation } \\
\text { Coefficient }\end{array}$ & - & - & - & - & \pm 0.2385 \\
\hline $\begin{array}{c}\text { Regression } \\
\text { Coefficient (b) }\end{array}$ & - & - & - & - & +0.0701 \\
\hline$P$ value & - & - & - & - & $<0.02$ \\
\hline
\end{tabular}

n.s. $=$ not significant.

Table-2: Maternal serum iron, T.I.B.C., Transferrin saturation and folate levels indifferent maternal haemoglobin groups (Mean \pm S.D.).

\begin{tabular}{|c|c|c|c|c|c|}
\hline Group & $\begin{array}{c}\text { Range of haemoglobin } \\
(\mathrm{g} \%)\end{array}$ & $\begin{array}{l}\text { Serum iron } \\
(\mathbf{u g} \%)\end{array}$ & T.I.B.C. (ug\%) & $\begin{array}{c}\text { Transerrin } \\
\text { saturation }(\%)\end{array}$ & $\begin{array}{l}\text { Serum folate } \\
\text { (ng/ml.) }\end{array}$ \\
\hline I & $\begin{array}{l}\leq 6.0 \\
(25)\end{array}$ & $\begin{array}{r}43.6 \\
\pm 25.12 \\
\end{array}$ & $\begin{array}{c}297.0 \\
\pm 149.73\end{array}$ & $\begin{array}{c}16.6 \\
\pm 10.85 \\
\end{array}$ & $\begin{array}{c}1.6 \\
\pm 1.02 \\
\end{array}$ \\
\hline II & $\begin{array}{c}6.1-8.5 \\
(21)\end{array}$ & $\begin{aligned} & 51.7 \\
& \pm 29.90 \\
&\end{aligned}$ & $\begin{array}{c}370.2 \\
\pm 154.45 \\
\end{array}$ & $\begin{array}{r}17.1 \\
\pm 13.20 \\
\end{array}$ & $\begin{array}{c}2.3 \\
\pm 2.16 \\
\end{array}$ \\
\hline III & $\begin{array}{c}8.6-10.9 \\
(42)\end{array}$ & $\begin{array}{c}62.4 \\
\pm 29.76\end{array}$ & $\begin{array}{c}327.2 \\
\pm 142.29\end{array}$ & $\begin{array}{c}23.4 \\
\pm 13.77\end{array}$ & $\begin{array}{c}4.0 \\
\pm 3.90\end{array}$ \\
\hline IV & $\begin{array}{l}\geq 11.0 \\
(23)\end{array}$ & $\begin{array}{c}82.2 \\
\pm 21.70\end{array}$ & $\begin{array}{c}196.1 \\
\pm 80.04\end{array}$ & $\begin{array}{c}46.0 \\
\pm 15.98\end{array}$ & $\begin{array}{c}3.1 \\
\pm 2.41\end{array}$ \\
\hline & Total observations & $\begin{array}{c}60.2 \\
\pm 30.05 \\
\end{array}$ & $\begin{array}{r}297.9 \\
\pm 140.26 \\
\end{array}$ & $\begin{array}{c}24.9 \\
\pm 17.28 \\
\end{array}$ & $\begin{array}{c}3.0 \\
\pm 2.90 \\
\end{array}$ \\
\hline \multicolumn{6}{|c|}{$P$ value } \\
\hline & $\mathrm{I} / \mathrm{IV}$ & $<0.001$ & $<0.01$ & $<0.001$ & $<0.001$ \\
\hline & II/IV & $<0.001$ & $<0.001$ & $<0.001$ & n.s. \\
\hline & III/IV & $<0.01$ & $<0.001$ & $<0.001$ & n.s. \\
\hline & rrelation Coefficient & +0.4529 & - & - & +0.2092 \\
\hline Reg & ression Coefficient (b) & +4.7032 & - & - & 0.2162 \\
\hline & $\mathrm{P}$ value & $<0.001$ & - & - & 0.05 \\
\hline
\end{tabular}




\section{Original Research Article}

Table-3: Two way frequency distribution of pregnant women in relation to maternal haemoglobin and serum albumin levels.

\begin{tabular}{|c|c|c|c|c|c|c|c|c|}
\hline \multirow[t]{3}{*}{ Group } & \multirow{3}{*}{$\begin{array}{c}\text { Haemoglobin } \\
(\mathrm{g} \%)\end{array}$} & \multirow{3}{*}{$\begin{array}{l}\text { No. of pregnant } \\
\text { women }\end{array}$} & \multicolumn{6}{|c|}{ Serum albumin } \\
\hline & & & \multicolumn{2}{|c|}{$<2.25$} & \multicolumn{2}{|c|}{$2.25-3.00$} & \multicolumn{2}{|c|}{$3.05-3.75>3.75$} \\
\hline & & & $\mathbf{N}$ & $\%$ & $\mathbf{N}$ & $\%$ & $\mathbf{N}$ & $\mathbf{N}$ \\
\hline I & $\leq 6.0$ & 25 & 9 & 36.0 & 15 & 60.0 & 0 & 1 \\
\hline II & $6.1-8.5$ & 21 & 3 & 14.3 & 12 & 57.1 & 1 & 5 \\
\hline III & $8.6-10.9$ & 42 & 10 & 23.8 & 18 & 42.9 & 7 & 7 \\
\hline IV & $\geq 11.0$ & 23 & 0 & 0 & 16 & 69.6 & 6 & 1 \\
\hline \multicolumn{2}{|c|}{ Total } & 111 & 22 & 19.8 & 61 & 54.9 & 14 & 14 \\
\hline
\end{tabular}

$\mathrm{N}=$ number of pregnant women.

Table-4: Prevalence of serum iron and serum folate deficiency in different maternal haemoglobin groups.

\begin{tabular}{|c|c|c|c|c|c|c|c|c|c|c|c|c|c|c|}
\hline \multirow[t]{3}{*}{ Group } & \multirow[t]{3}{*}{$\begin{array}{c}\text { Haemoglobin } \\
(\mathrm{g} \%)\end{array}$} & \multirow[t]{3}{*}{$\begin{array}{c}\begin{array}{c}\text { Number } \\
\text { of } \\
\text { pregnant } \\
\text { women }\end{array} \\
\end{array}$} & \multicolumn{4}{|c|}{ Serum iron (ug \%) } & \multicolumn{4}{|c|}{ Serum folate (ng/ml) } & \multirow{2}{*}{\multicolumn{2}{|c|}{$\begin{array}{c}\text { Serum iron } \\
<50.0(\text { ug } \%) \& \\
\text { serum folate } \\
<3.0 \mathrm{ng} / \mathrm{ml} \\
\end{array}$}} & \multirow{2}{*}{\multicolumn{2}{|c|}{$\begin{array}{c}\text { Serum iron } \\
50-80 u g \% \\
\text { Serum folate } \\
\text { ng/ml 3.0-5.9 }\end{array}$}} \\
\hline & & & \multicolumn{2}{|c|}{$<50.0$} & \multicolumn{2}{|c|}{$50.0-80.0$} & \multicolumn{2}{|c|}{3.0} & \multicolumn{2}{|c|}{$3.0-5.9$} & & & & \\
\hline & & & $\mathrm{N}$ & $\%$ & $\mathrm{~N}$ & $\%$ & $\mathrm{~N}$ & $\%$ & $\mathrm{~N}$ & $\%$ & $\mathrm{~N}$ & $\%$ & $\mathrm{~N}$ & $\%$ \\
\hline I & $\leq 6.0$ & 25 & 3 & 12.0 & 1 & 4.0 & 7 & 28.0 & 0 & 0 & 13 & 52.2 & 1 & 4.0 \\
\hline II & $6.1-8.5$ & 20 & 3 & 15.0 & 1 & 5.0 & 6 & 30.0 & 1 & 5.0 & 7 & 35.0 & 2 & 10.0 \\
\hline III & $8.6-10.9$ & 40 & 8 & 20.0 & 1 & 2.5 & 15 & 37.5 & 4 & 10.0 & 4 & 10.0 & 8 & 20.0 \\
\hline IV & $\geq 11.0$ & 21 & 0 & 0 & 2 & 9.5 & 6 & 28.6 & 6 & 28.6 & 1 & 4.8 & 6 & 28.6 \\
\hline & Total & 106 & 14 & 13.2 & 5 & 4.7 & 34 & 32.1 & 11 & 10.4 & 25 & 23.59 & 14 & 13.2 \\
\hline
\end{tabular}

Table-5: Effect of therapy with haematinics and protein on maternal haemoglobin, haematocrit, serum proteins, iron, and folate levels.

\begin{tabular}{|c|c|c|c|c|c|c|c|c|c|}
\hline $\begin{array}{c}\text { Range of } \\
\text { haemoglobin } \\
(\mathrm{g} \%)\end{array}$ & Group & $\begin{array}{l}\text { Gestation } \\
\text { (weeks) }\end{array}$ & $\begin{array}{c}\text { Haemoglobin } \\
(\mathrm{g} \%)\end{array}$ & $\begin{array}{c}\text { Haematocrit } \\
(\%)\end{array}$ & \begin{tabular}{|c|} 
Total serum \\
protein \\
$(\mathrm{g} \%)$
\end{tabular} & $\begin{array}{l}\text { Serum } \\
\text { albumin } \\
(\mathrm{g} \%)\end{array}$ & $\begin{array}{l}\text { Serum } \\
\text { iron } \\
(\mathrm{g} \%)\end{array}$ & $\begin{array}{c}\text { Transferrin } \\
\% \\
\text { saturation }\end{array}$ & $\begin{array}{c}\text { Serum } \\
\text { folate } \\
\mathrm{ng} / \mathrm{ml}\end{array}$ \\
\hline \multirow[t]{7}{*}{$\leq 6.0$} & $\begin{array}{l}\text { I Anaemic } \\
\text { group (12) }\end{array}$ & $\begin{array}{c}37 \\
\pm 0.75\end{array}$ & $\begin{array}{c}47 \\
\pm 0.86\end{array}$ & $\begin{array}{c}13.6 \\
\pm 2.43\end{array}$ & $\begin{array}{c}4.4 \\
\pm 0.57\end{array}$ & $\begin{array}{c}2.1 \\
\pm 0.36\end{array}$ & $\begin{array}{c}43.0 \\
\pm 14.91\end{array}$ & $\begin{array}{c}14.9 \\
\pm 4.06\end{array}$ & $\begin{array}{c}0.87 \\
\pm 0.45\end{array}$ \\
\hline & \multicolumn{9}{|c|}{ II Treatment group (7) } \\
\hline & $\begin{array}{l}\text { a. before } \\
\text { treatment }\end{array}$ & $\begin{array}{l}24.0 \\
\pm 3.3\end{array}$ & $\begin{array}{c}4.8 \\
\pm 1.01\end{array}$ & $\begin{array}{c}15.4 \\
\pm 2.15\end{array}$ & $\begin{array}{c}4.5 \\
\pm 2.15\end{array}$ & $\begin{array}{c}2.3 \\
\pm 0.36\end{array}$ & $\begin{array}{c}34.4 \\
\pm 9.37\end{array}$ & $\begin{array}{l}16.5 \\
\pm 5.0\end{array}$ & $\begin{array}{c}2.0 \\
\pm 0.89\end{array}$ \\
\hline & $\begin{array}{l}\text { a. after } \\
\text { treatment }\end{array}$ & $\begin{array}{c}38.1 \\
\pm 1.35 \\
\end{array}$ & $\begin{array}{l}10.6 \\
\pm 2.0\end{array}$ & $\begin{array}{c}31.1 \\
\pm 6.62 \\
\end{array}$ & $\begin{array}{c}5.8 \\
\pm 0.56 \\
\end{array}$ & $\begin{array}{c}3.1 \\
\pm 0.52 \\
\end{array}$ & $\begin{array}{c}55.6 \\
\pm 23.85 \\
\end{array}$ & $\begin{array}{c}31.4 \\
\pm 16.37 \\
\end{array}$ & $\begin{array}{c}2.6 \\
\pm 1.53 \\
\end{array}$ \\
\hline & $P$ values & & & & & & & & \\
\hline & I/IIb & & $<0.001$ & $<0.001$ & $<0.001$ & $<0.005$ & n.s. & $<0.005$ & $<0.05$ \\
\hline & II/IIb & & $<0.001$ & $<0.001$ & $<0.005$ & $<0.01$ & $<0.05$ & $<0.05$ & n.s. \\
\hline \multirow[t]{15}{*}{ 6.1-8.5 } & $\begin{array}{l}\text { I anaemicgroup } \\
\text { (15) }\end{array}$ & $\begin{array}{c}7.1 \\
\pm 0.76 \\
\end{array}$ & $\begin{array}{c}22.0 \\
\pm 2.83 \\
\end{array}$ & $\begin{array}{c}4.6 \\
\pm 0.57 \\
\end{array}$ & $\begin{array}{c}2.3 \\
\pm 0.29 \\
\end{array}$ & $\begin{array}{r}44.5 \\
\pm 0.29 \\
\end{array}$ & $\begin{array}{c}18.8 \\
\pm 4.12 \\
\end{array}$ & $\begin{array}{c}1.5 \\
\pm 1.12 \\
\end{array}$ & $\begin{array}{c}1.5 \\
\pm 1.12 \\
\end{array}$ \\
\hline & \multicolumn{9}{|c|}{ II Treated group (10) } \\
\hline & $\begin{array}{l}\text { a. Before } \\
\text { therapy }\end{array}$ & $\begin{array}{c}23.4 \\
\pm 2.70 \\
\end{array}$ & $\begin{array}{c}7.4 \\
\pm 0.94 \\
\end{array}$ & $\begin{array}{c}22.6 \\
\pm 2.63 \\
\end{array}$ & $\begin{array}{c}4.9 \\
\pm 0.74\end{array}$ & $\begin{array}{c}2.5 \\
\pm 0.69\end{array}$ & $\begin{array}{c}46.7 \\
\pm 27.29\end{array}$ & $\begin{array}{c}15.7 \\
\pm 7.74\end{array}$ & $\begin{array}{c}2.2 \\
\pm 1.93\end{array}$ \\
\hline & $\begin{array}{l}\text { b. After } \\
\text { therapy }\end{array}$ & $\begin{array}{c}38.4 \\
\pm 1.46\end{array}$ & $\begin{array}{c}12.1 \\
\pm 1.72\end{array}$ & $\begin{array}{c}34.4 \\
\pm 5.76\end{array}$ & $\begin{array}{c}5.8 \\
\pm 0.83\end{array}$ & $\begin{array}{c}3.2 \\
\pm 0.75\end{array}$ & $\begin{array}{c}71.8 \\
\pm 22.31\end{array}$ & $\begin{array}{c}34.5 \\
\pm 19.39\end{array}$ & $\begin{array}{c}3.3 \\
\pm 2.65\end{array}$ \\
\hline & \multicolumn{9}{|l|}{ P values } \\
\hline & I/IIb & & $<0.001$ & $<0.001$ & $<0.001$ & $<0.001$ & $<0.005$ & $<0.005$ & n.s. \\
\hline & IIa/IIb & & $<0.001$ & $<0.001$ & $<0.025$ & n.s. & $<0.05$ & $<0.02$ & n.s. \\
\hline & \multicolumn{9}{|c|}{ Total observation } \\
\hline & $\begin{array}{l}\text { I Anamic } \\
\text { group (27) }\end{array}$ & & $\begin{array}{c}6.1 \\
\pm 1.46\end{array}$ & $\begin{array}{c}18.3 \\
\pm 4.99\end{array}$ & $\begin{array}{c}4.5 \\
\pm 0.57\end{array}$ & $\begin{array}{c}2.3 \\
\pm 0.33\end{array}$ & $\begin{array}{c}44.5 \\
\pm 14.97\end{array}$ & $\begin{array}{c}17.1 \\
\pm 4.46\end{array}$ & $\begin{array}{c}1.2 \\
\pm 0.9\end{array}$ \\
\hline & \multicolumn{9}{|c|}{ II Treated group (17) } \\
\hline & $\begin{array}{l}\text { a. Before } \\
\text { therapy }\end{array}$ & $\begin{array}{r}23.9 \\
\pm 2.69\end{array}$ & $\begin{array}{c}6.3 \\
\pm 1.61\end{array}$ & $\begin{array}{c}19.7 \\
\pm 4.34\end{array}$ & $\begin{array}{c}4.8 \\
\pm 0.73\end{array}$ & $\begin{array}{c}2.4 \\
\pm 0.58\end{array}$ & $\begin{array}{c}41.7 \\
\pm 22.21 \\
\end{array}$ & $\begin{array}{c}16.0 \\
\pm 6.58\end{array}$ & $\begin{array}{c}2.09 \\
\pm 1.49\end{array}$ \\
\hline & $\begin{array}{l}\text { b. after } \\
\text { therapy }\end{array}$ & $\begin{array}{c}38.3 \\
\pm 1.36\end{array}$ & $\begin{array}{c}11.5 \\
\pm 1.92\end{array}$ & $\begin{array}{c}34.2 \\
\pm 6.49\end{array}$ & $\begin{array}{c}5.8 \\
\pm 0.71\end{array}$ & $\begin{array}{c}3.1 \\
\pm 0.64\end{array}$ & $\begin{array}{c}5.1 \\
\pm 23.69\end{array}$ & $\begin{array}{c}34.2 \\
\pm 17.73\end{array}$ & $\begin{array}{c}3.07 \\
\pm 2.31\end{array}$ \\
\hline & \multicolumn{9}{|l|}{ P values } \\
\hline & I/II b & & $<0.001$ & $<0.001$ & $<0.001$ & $<0.001$ & $<0.001$ & $<0.001$ & $<0.001$ \\
\hline & IIa/IIb & & $<0.001$ & $<0.001$ & $<0.001$ & $<0.005$ & $<0.01$ & $<0.001$ & n.s. \\
\hline
\end{tabular}




\section{Original Research Article}

The serum iron in mothers with severe, moderate and mild anaemia were significantly less than those in the mother without anaemia. Out of 111 patients $34.2 \%$ had serum iron below $50.0 \mathrm{ug} \%$. And among the 88 anaemic patients $84.1 \%$ had serum iron below $\leq 80.0 \mathrm{ug} \%$. The percentage of women with serum iron less than $50.0 \mathrm{ug} \%$ showed a steady decrease with increase in haemoglobin. Further serum iron was found to have a linear correlation with maternal haemoglobin levels. Transfer in saturation in mothers with severe moderate and mild anaemia was significantly less than those in mothers without anaemia. Out of 111 patients $41.4 \%$ had transferrin saturation $\leq 16.0 \%$ and among the 88 anaemic patients $55.3 \%$ had transferrin saturation above 16.0 or below, $47.7 \%$ had transferrin saturation above $16.0 \%$. The percentage of pregnant women with transferrin saturation $\leq 16.0$ showed a steady decrease with increase in serum iron had haemoglobin.

Table-6: Effect of therapy with hameatinic and proteins on birth weight and placental tissue.

\begin{tabular}{|c|c|c|c|c|c|c|c|}
\hline \multirow{2}{*}{$\begin{array}{c}\text { Range of } \\
\text { haemoglobin } \\
(\mathrm{g} \%)\end{array}$} & \multirow[t]{2}{*}{ Group } & \multirow{2}{*}{$\begin{array}{l}\text { Birth } \\
\text { weight } \\
\text { (g) }\end{array}$} & \multicolumn{4}{|c|}{ Placenta } & \multirow{2}{*}{$\begin{array}{l}\text { Placental } \\
\text { coefficient }\end{array}$} \\
\hline & & & $\begin{array}{c}\text { Weight } \\
\text { (g) }\end{array}$ & $\begin{array}{l}\text { Volume } \\
\text { (ml) }\end{array}$ & $\begin{array}{c}\text { Surface } \\
\text { area }\end{array}$ & $\begin{array}{l}\text { Number of } \\
\text { cotyledons }\end{array}$ & \\
\hline \multirow[t]{4}{*}{$\leq 6.0$} & $\begin{array}{l}\text { I Anaemic group } \\
\text { (12) }\end{array}$ & $\begin{array}{c}2041.7 \\
\pm 217.38\end{array}$ & $\begin{array}{c}337.5 \\
\pm 73.22\end{array}$ & $\begin{array}{c}315.0 \\
\pm 83.72\end{array}$ & $\begin{array}{c}201.1 \\
\pm 27.73\end{array}$ & $\begin{array}{c}9.7 \\
\pm 1.73\end{array}$ & $\begin{array}{c}0.168 \\
\pm 0.036\end{array}$ \\
\hline & $\begin{array}{l}\text { II } b \text { treated group } \\
\text { (7) }\end{array}$ & $\begin{array}{c}2916.7 \\
\pm 334.48\end{array}$ & $\begin{array}{c}420.6 \\
\pm 62.17\end{array}$ & $\begin{array}{c}422.9 \\
\pm 100.78\end{array}$ & $\begin{array}{c}290.5 \\
\pm 86.55\end{array}$ & $\begin{array}{c}14.1 \\
\pm 86.55\end{array}$ & $\begin{array}{c}0.156 \\
\pm 0.019\end{array}$ \\
\hline & Change & +875.0 & +83.1 & +107.9 & +88.4 & +4.4 & 0.012 \\
\hline & $P$ values & $<0.01$ & $<0.02$ & $<0.02$ & $<0.001$ & $<0.001$ & n.s. \\
\hline \multirow[t]{9}{*}{$6.1-8.5$} & $\begin{array}{l}\text { I Anaemic group } \\
(15)\end{array}$ & $\begin{array}{c}2226.3 \\
\pm 248.59 \\
\end{array}$ & $\begin{array}{c}380.0 \\
\pm 41.45 \\
\end{array}$ & $\begin{array}{c}348.7 \\
\pm 51.39 \\
\end{array}$ & $\begin{array}{c}249.9 \\
\pm 29.94 \\
\end{array}$ & $\begin{array}{c}12.5 \\
\pm 0.92 \\
\end{array}$ & $\begin{array}{c}0.185 \\
\pm 0.026 \\
\end{array}$ \\
\hline & $\begin{array}{l}\text { II } b \text { treated group } \\
(10)\end{array}$ & $\begin{array}{c}3080.6 \\
\pm 591.78 \\
\end{array}$ & $\begin{aligned} & 531.8 \\
& \pm 108.85 \\
&\end{aligned}$ & $\begin{array}{r}454.0 \\
\pm 127.0 \\
\end{array}$ & $\begin{array}{c}284.9 \\
\pm 57.19\end{array}$ & $\begin{array}{r}13.1 \\
\pm 1.79 \\
\end{array}$ & $\begin{array}{c}0.16 \\
\pm 0.031 \\
\end{array}$ \\
\hline & Change & +854.6 & +151.6 & +105.3 & +35.8 & +0.6 & 0.022 \\
\hline & $\mathrm{P}$ values & $<0.001$ & $<0.001$ & $<0.001$ & n.s. & n.s. & n.s. \\
\hline & $\mathrm{I} / \mathrm{IIb}$ & & & & & & \\
\hline & \multicolumn{7}{|c|}{ Total observation } \\
\hline & $\begin{array}{l}\text { I (27) Anaemic } \\
\text { group }\end{array}$ & $\begin{array}{c}2032.2 \\
\pm 253.50 \\
\end{array}$ & $\begin{array}{r}361.2 \\
\pm 60.47 \\
\end{array}$ & $\begin{array}{c}337.7 \\
\pm 68.39 \\
\end{array}$ & $\begin{array}{l}221.56 \\
\pm 27.92 \\
\end{array}$ & $\begin{array}{l}11.11 \\
\pm 1.44\end{array}$ & $\begin{array}{l}0.178 \\
\pm 0.03\end{array}$ \\
\hline & $\begin{array}{l}\text { IIb(17) treated } \\
\text { group }\end{array}$ & $\begin{array}{c}3015.0 \\
\pm 496.96 \\
\end{array}$ & $\begin{array}{r}489.9 \\
\pm 104.29 \\
\end{array}$ & $\begin{array}{c}441.2 \\
\pm 114.78 \\
\end{array}$ & $\begin{array}{r}287.3 \\
\pm 68.24 \\
\end{array}$ & $\begin{array}{r}13.5 \\
\pm 1.91 \\
\end{array}$ & $\begin{array}{c}0.16 \\
\pm 0.026 \\
\end{array}$ \\
\hline & $P$ values & $<0.001$ & $<0.001$ & $<0.001$ & $<0.001$ & $<0.001$ & n.s. \\
\hline
\end{tabular}

In our study there was significant improvement in the birth weight in both the groups, the increase being around 40-43 per cent. In contrast the increase in placental weight 40 percent in the haemoglobin group 6.1-8.5 g per cent as compared to the increase of 25.0 per cent in the haemoglobin group 6.0 per cent or below it. The placental weight in treated group (6.1-5.5 g percent) was $531.8 \mathrm{~g}$ while the mean placental weight in haemoglobin group $<6.0 \mathrm{~g}$ per cent or below was $420.6 \mathrm{~g}$.

Although the difference was $111.2 \mathrm{~g}$ this was not statistically significant due to limited number of observation. The placental volume change in both group were similar. The number of cotyledons significantly increase in haemoglobin group $6.0 \mathrm{~g}$ per cent or below while no change was observed in the moderate anaemicgroup.In the low haemoglobin group the gain for birth weight, placental weight, volume, surface area and number of cotyledons were found to be statistically significant.

The birth weight, placental weight and volume were also significantly increased with treatment in group 6.1-8.5 g per cent while surface area and number of cotyledons did not show any significant change. The change in placental coefficient in anaemic and treated anaemic group was not found to significant in both the haemoglobin groups. 


\section{Discussion}

An effort has been made to study anaemia in pregnancy by a detailed evaluation of maternal serum iron, folate and protein contents. The plan was to study the effect of replacement therapy in at least half the number of cases, where the treatment could be started at about 20-28 weeks, so that there were about 12-16 weeks for improvement in the foeto-placental axis to occur, if any. 46- anamic mothers $(\mathrm{Hb} \leq 8.5 \mathrm{~g} \%)$ were treated with haematinics, proteins after antihelminthics for parasites.

Only 17 could be followed to term. Their maternal, cord blood and placental studies were done to assess the effect of treatment on foeto-placental axis, and their respective values were compared with 27 anaemic patients delivered in this hospital at term who were not treated for anaemia. 30 anaemic women were primigravida and the rest 58 were multipara.

The incidence of anaemia in primigravida was relatively high, as only 6 of them had history of chronic diarrhea and $30 \%$ had GIT worm infestation. It is likely that these cases were already anaemic before embarking on pregnancy.

Carriaga MT, Skikne BS et al did their study on serum transferrin receptor for the detection of iron deficiency in pregnancy. Measurements of circulating transferring receptor provide a sensitive quantitative index of tissue iron deficiency in otherwise healthy subjects. This investigation was undertaken to examine the diagnostic utility of this new iron index in pregnancy. A battery of iron-related measurements, including serum transferrin receptor concentrations, was performed on 176 women in third-trimester pregnancy who were attending a university prenatal clinic. The mean receptor concentration of $5.96+/-2.37 \mathrm{mg} / \mathrm{L}(+/-1 \mathrm{SD})$ did not differ significantly from concentrations in nonpregnant individuals and the frequency distributions were likewise comparable.

Elevations in serum receptor greater than $8.5 \mathrm{mg} / \mathrm{L}$ occurred only in women with depleted iron stores defined by serum ferritin concentrations. Abnormal concentrations were found in 11 of 13 women with overt iron-deficiency anemia.

Findings indicate that serum receptor concentrations are not influenced by pregnancy per se and are a sensitive index of iron deficiency. By combining serum receptor and serum ferritin measurements, the entire spectrum of iron status in pregnancy can be assessed $[6,7]$.
Black RE. studied micronutrients in pregnancy and found that $\mathrm{Hb}$ level alone is insufficient to guide management. A complete work-up (ferritin, transferrin saturation) is essential, preferably with hematological indices such as hypochromic and microcytic red cells and reticulocytes, classified by degree of maturity, in particular, before parenteral therapy is given. Since ferritin acts as both an iron-storage and acute-phase protein, it cannot be used to evaluate iron status in the presence of inflammation.

A high ferritin level thus requires the presence fo an inflammatory process to be eliminated before it can be taken at face value[8]. Allen LH studiedAnemia and iron deficiency. They reviewed current knowledge of the effects of maternal anemia and iron deficiency on pregnancy outcome.

A considerable amount of information remains to be learned about the benefits of maternal iron supplementation on the health and iron status of the mother and her child during pregnancy and postpartum. Mounting evidence indicates that maternal iron deficiency in pregnancy reduces fetal iron stores, perhaps well into the first year of life.

This deserves further exploration because of the tendency of infants to develop iron deficiency anemia and because of the documented adverse consequences of this condition on infant development. The weight of evidence supports the advisability of routine iron supplementation during pregnancy $[9,10,11]$.

Rohilla M, Raveendran Aetal under took study to determine the maternal and perinatal outcome in patients with severe anaemia in pregnancy, with a haemoglobin concentration of $<7 \mathrm{~g} / \mathrm{dl}$. The in-hospital data were analysed for 12 months and $2.15 \%(n=96)$ of women were found to have severe anaemia. Out of these, $18.75 \%$ had pre-term premature rupture of membranes and $5.12 \%$ of all deliveries were pre-term.

Hypertensive diseases of pregnancy were seen in $17.7 \%$; abruption in $3.12 \%$ and $9.37 \%$ had congestive cardiac failure. Postpartum haemorrhage was seen in $25.5 \%$ of the patients and $8.33 \%$ had puerperal pyrexia.

Fetal distress was seen in $26 \%$ of and $33.33 \%$ had small for gestational age neonates; there were $16.66 \%$ stillbirths and $4.16 \%$ neonatal deaths. Of the 96 severely anaemic women, six died after admission. Our study 


\section{Original Research Article}

also shows that efforts must be taken towards safe motherhood and spreading awareness about the various consequences of anaemia, which is usually preventable with early correction[12]. Sferruzzi-Perri AN, Vaughan OR et al did their work on nutrients that drive intrauterine growth by providing substrate for tissue accretion, whereas hormones regulate nutrient distribution between foetal oxidative metabolism and mass accumulation.

By responding to nutrient and oxygen availability, foetal hormones optimize the survival and growth of the foetus with respect to its genetic potential, particularly during adverse conditions. However, changes in the intrauterine growth of individual tissues may alter their function permanently.

In both normal and compromised pregnancies, intrauterine growth is determined by multiple hormonal and nutritional drivers which interact to produce a specific pattern of intrauterine development with potential lifelong consequences for health $[13,14]$.

\section{Conclusion}

Out of 88 anaemic mothers $85(96.6 \%)$ had either serum iron or folate deficiency or both. $19.3 \%$ patients had pure iron deficiency. $37.5 \%$ had pure folate deficiency.39.8\% had combined iron and folate deficiency. Control group with haemoglobin $\geq 11.0 \mathrm{~g} \%$ had significant number of women with folate, iron, or both deficiency.

The severe anaemia was associated with low proteins and albumin indicating that severe anaemia often coexists with hypoproteinamia. There was marked improvement in birth weight and placental weight with haematinic and protein therapy of about 14 weeks.

The maternal, cord blood and placental haemoglobin showed significant improvement after therapy.

\section{Ethical approval: Taken}

What this study add to existing knowledge: Correction of anaemia with haematinics and proteins provides a reasonable good indicators of their deficiency in pregnancy.

There was marked improvement in birth weight and placental weight with haematinic and protein therapy of about 14 weeks. The maternal, cord blood and placental haemoglobin showed significant improvement after therapy.

\section{Funding: Nil, Conflict of interest: Nil \\ Permission from IRB: Yes}

\section{References}

1. Agarwal KN, Agarwal DK, Sharma A, Sharma K. Prevalence of anaemia in pregnant \& lactating women in India. Indian journal of medical research. 2006 Aug $1 ; 124(2): 173$.

2. Kaur IP, Kaur S. A comparison of nutritional profile and prevalence of anemia among rural girls and boys. Journal of Exercise Science and Physiotherapy. 2011 Jun; 7(1):11.

3. Pathak P, Singh P, Kapil U, Raghuvanshi RS. Prevalence of iron, vitamin A, and iodine deficiencies amongst adolescent pregnant mothers. The Indian Journal of Pediatrics. 2003 Apr 1; 70 (4): 299301.

4. Pathak P, Kapil U, Kapoor SK, Saxena R, Kumar A, Gupta N, Dwivedi SN, Singh R, Singh P. Prevalence of multiple micronutrient deficiencies amongst pregnant women in a rural area of Haryana. The Indian Journal of Pediatrics. 2004 Nov 1;71(11):1007-14.

5. Myatt L. Placental adaptive responses and fetal programming. The Journal of physiology. 2006 Apr $1 ; 572(1): 25-30$.

6. Goonewardene M, Shehata M, Hamad A. Anaemia in pregnancy. Best practice \& research Clinical obstetrics \& gynaecology. 2012 Feb 29; 26(1):3-24.

7. Carriaga MT, Skikne BS, Finley B, Cutler B, Cook JD. Serum transferrin receptor for the detection of iron deficiency in pregnancy. The American journal of clinical nutrition. 1991 Dec 1;54(6):1077-81.

8. Black RE. Micronutrients in pregnancy. British Journal of Nutrition. 2001 May 1;85 (S2) : S193-7.

9. Breymann C. Iron deficiency and anaemia in pregnancy: modern aspects of diagnosis and therapy. European Journal of Obstetrics \& Gynecology and Reproductive Biology. 2005 Dec 1; 123: S3-13.

10. Allen LH. Anemia and iron deficiency: effects on pregnancy outcome. The American journal of clinical nutrition. 2000 May 1;71(5):1280s-4s. 


\section{Original Research Article}

11. Viveki RG, Halappanavar AB, Viveki PR, Halki SB, Maled VS, Deshpande PS. Prevalence of anaemia and its epidemiological determinants in pregnant women. Al Ameen J Med Sci. 2012;5(3):216-3.

12. Rohilla M, Raveendran A, Dhaliwal LK, Chopra S. Severe anaemia in pregnancy: a tertiary hospital experience from northern India. Journal of Obstetrics and Gynaecology. 2010 Oct 1;30(7):694-6.
13. Kalaivani K. Prevalence \& consequences of anaemia in pregnancy. Indian J Med Res. 2009 Nov 1; 130 (5):627-33.

14. Sferruzzi-Perri AN, Vaughan OR, Forhead AJ, Fowden AL. Hormonal and nutritional drivers of intrauterine growth. Current Opinion in Clinical Nutrition \& Metabolic Care. 2013 May1;16(3):298-309.

\section{How to cite this article?}

Nagar N, Mazumdar M. Anemia prevalence \& effect on feto-placental axis with treatment with iron, folic acid \& protein powder. Obs Rev: J obstet Gynecol 2019;5(1):45-52.doi:10.17511/joog.2019.i01.09. 